\title{
Editorial
}

\section{Gekkota Mundi - the world of geckos}

\author{
Shai Meiri* \\ School of Zoology, Faculty of Life Sciences, The Steinhardt Museum of Natural History, 12 Klausner Street, Tel-Aviv University, \\ Tel Aviv, 6997801, Israel
}

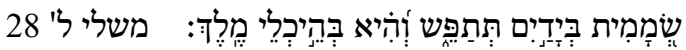

(The gecko can be caught by hand, and dwells in the kings' palaces. Proverbs 30: 28)

Geckos are immediately recognizable and, more so than any other reptile, they are literally household animals in warm regions the world over. Indeed, I think the original Hebrew text in Proverbs 30: 28 (above) refers neither to spiders, nor generally to "lizards", as most translations into English hold, but to 'שממית': 'smamit', the modern Hebrew name for geckos, and very similar to the Greek ' $\Sigma \alpha \mu \imath \mu \hat{i}^{\delta} \mathrm{\imath}$ ' ('Samiamidi'). The biblical description, an animal that is so gentle and delicate it can be safely caught by hand (more easily than many other lizards and, well, spiders inspire fear in more people) - yet can be found in any human dwelling, even the palaces of kings, fits the bill perfectly.

Geckos are incredibly diverse. If reptiles are the most diverse of land vertebrate groups (they are, with over 11,300 recognized species), geckos (Squamata: Gekkota) are the most diverse of reptiles. Over 2000 species were recognized as of August 2020 (Uetz 2020), and 15 more species were described in the few weeks since (e.g., Cyrtodactylus amphipetraeus, Chomdej et al. 2020; Dixonius dulayaphitakorum, Sumontha and Pauwels 2020, Hemidactylus rishivalleyensis and Cnemaspis rishivalleyensis, Agarwal et al. 2020; Goniurosaurus gezhi, Zhu et al. 2020, Hemiphyllodactylus minimus, Mohapatra et al. 2020, and Lygodactylus nyaneka, Marques et al. 2020, to name but a few). This is more than the recognized number of species of Scincomoprhs (skinks and allies; 1852 species), Iguanians (1222), and colubrid snakes (including natricines and dipsadines; 1977; Uetz 2020). Furthermore, no reptile taxa are being described nowadays quite as fast as geckos are (Meiri 2020, this volume), and these descriptions are mostly being carried out by $\sim 10$ highly prolific authors and together with their colleagues (Uetz et al. 2020; this volume).

Some of these hyper-prolific taxonomists, and other gecko enthusiasts who use geckos as model systems for the study of evolution, ecology and conservation, established the Gekkota-Mundi symposia that aim to serve the community of gecko biologists (and of scientists studying geckos in general) as a venue for exchanging findings, opinions, and ideas. Two Gekkota Mundi events have been held to date: the first in Fremantle, Western Australia, in June 2017, and the second in Tel Aviv, Israel in June 2019 (Fig. 1).

Several of the talks presented in the Gekkota Mundi symposia were subsequently written up for this special issue of the Israel Journal of Ecology and Evolution.

The first group of papers are concerned with taxonomy and phylogeny. In the first paper Uetz et al. (2020) describe the history of the scientific descriptions of geckos, tracking changes in the rates of species descriptions since 1758 (when Linnaeus described only three geckos) through the great monographs of the $19^{\text {th }}$ century (Duméril and Bibron 1836; Gray 1845; Boulenger 1885) to today's peak (see also Meiri 2016). Uetz et al. (2020) then proceed to identify the major research groups describing geckos (e.g., Gekkota Mundi founders Aaron Bauer, Lee Grismer, Paul Oliver and Paul Doughty), and the natural history museums holding gecko types (e.g., BMNH, MCZ, MNHN). They identify the richest gecko clades and genera, and the countries (mainly roughly around the Indian Ocean) where most gecko diversity resides (Uetz et al. 2020). In the second paper, Kealley et al. (2020) examine the taxonomy of two members of the Australian gecko radiation, one taxon of carphodactylids (Nephrurus wheeleri) and one of legless pygopods (Pletholax gracilis). In both taxa Kealley et al. (2020) identify deep genetic divergences that correspond to diagnostic morphological characters and distribution patterns. They therefore elevate two subspecies to species rank, recognizing Pletholax edelensis Storr, 1978 as distinct from P. gracilis (Schlegel 1865) and Nephrurus

\footnotetext{
* Corresponding author. E-mail: uncshai@tauex.tau.ac.il
} 

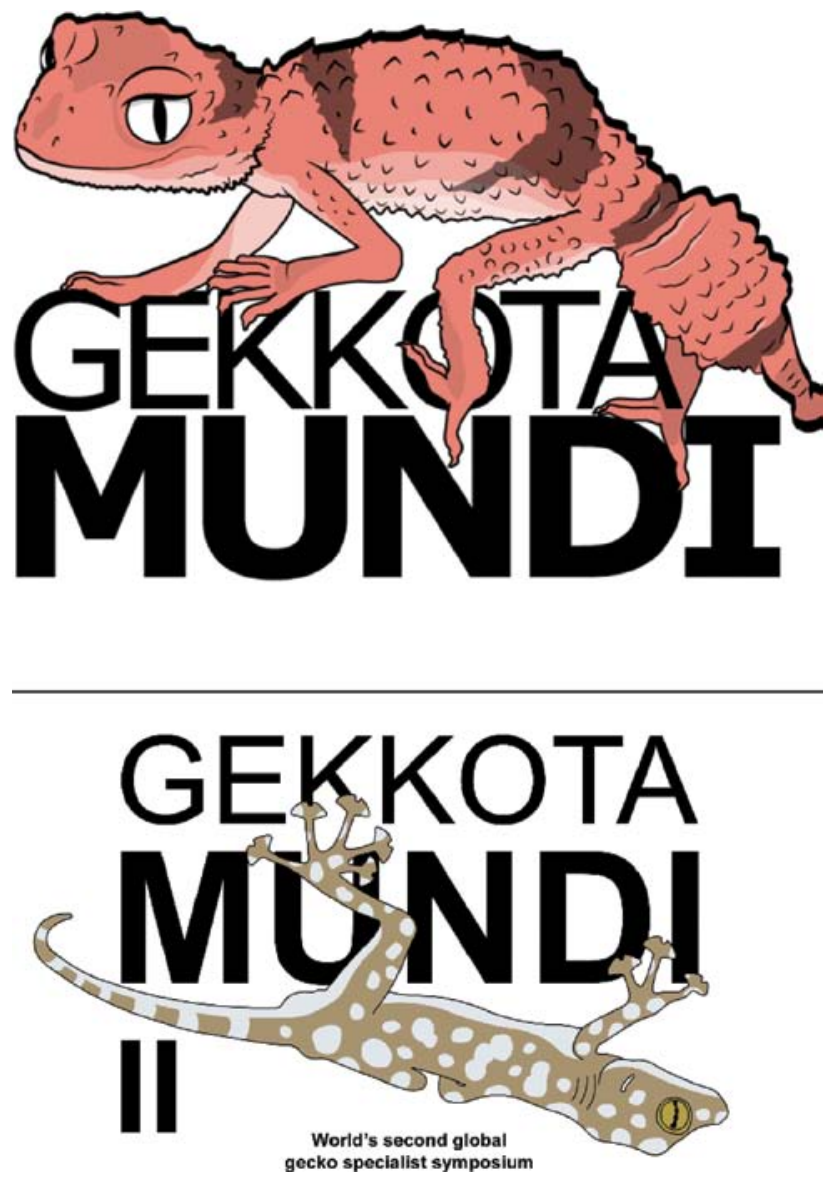

Figure 1. The logos of Gekkota Mundi I (top) and II (bottom). The species are Nephrurus cinctus (top) and Ptyodactylus guttatus (bottom).

cinctus Storr 1963 (the logo species of Gekkota Mundi I, see Fig. 1) as distinct from $N$. wheeleri Loveridge 1932.

In the third paper Worthington Wilmer et al. (2020) also study pygopods. They examine the phylogeography of two recognized woodland species of these fascinating legless gekkotans from the Brigalow Belt Bioregion of eastern Queensland. Worthington Wilmer et al. (2020) find low genetic divergence and no genetic structure in the large, semi arboreal Paradelma orientalis, and stronger genetic structure associated with medium levels of genetic divergence in the smaller, semi-fossorial species, Delma torquata. They then discuss how the ecological differences between the two species could lead to these different patterns. In the fourth paper, Grismer et al. (2020a) examine the genetic and morphological differentiation in allopatric populations of the granite-dwelling gecko Cyrtodactylus aequalis from Myanmar (Burma). They find discordance between the morphological evidence, that could be advanced to advocate splitting $C$. aequalis into three species, and the genetic data that suggest only one species should be recognized. Grismer et al. (2020a) contend that gene flow may be occurring between the putatively allopatric populations, preventing speciation but not preventing adaptations (which manifest in different morphologies) to local conditions.

In the fifth paper, Karkkainen et al. (2020) describe a new species of gekkonid gecko from Salawati Island, near the Indonesian part of New Guinea. The new species, Lepidodactylus pollostos is known only from its holotype, an adult male. Karkkainen et al. (2020) go on to claim that, as far as is known, at $32.5 \mathrm{~mm}$ snout-vent length, L. pollostos is the smallest of the 41 Lepidodactylus species.

The second group of papers deal with ecology and evolution. In the sixth paper overall Oliver et al. (2020) examine the elevational distributions of geckos ranging from Sumatra and the Malay/Thai Peninsula in the west, through Indonesia to Papua New-Guinea in the East, and the Philippines in the north. They find that mountain taxa are usually highly divergent from even their closest lowland relatives. Oliver et al. (2020) posit that these geckos are restricted to mountains due to competition with lowland taxa. Thus, global warming bodes ill for their probability of future survival because the competing lowland species will be able to shift their distributions upwards, potentially displacing the mountain endemics (Oliver et al. 2020). In the seventh paper Grismer et al. (2020b) discusses the Burmese species of the incredibly diverse genus Cyrtodactylus (305 species, the second-largest reptile genus, 71 of which were described by Lee Grismer and his group; Uetz 2020; this volume). They find that most (58\%) of the Cyrtodactylus in Myanmar are karst-habitat endemics, and that the association with karst independently evolved at least for times in this group. They point out that many karst habitats in Myanmar and elsewhere in SE Asia remain to be surveyed - thus large numbers of undescribed Cyrtodactylus species are likely to occur in this region (Grismer et al. 2020b). Grismer et al. (2020b) further note that karst habitats are under increasing pressure from mining and are not protected by current legislation. The karst-dwelling species are therefore often at great peril.

In the eighth paper Riedel et al. (2020) examine microhabitat use in a large assemblage of geckos from Queensland, Australia. Riedel et al. (2020) quantify the proportion of time each species in the assemblage spend in different microhabitats (ground, trees, rocks etc.). They go on to classify the diameters of surfaces and the heights these geckos were observed perching on. They show that arboreal members are generally aligned with the ecomorph categories designated for other lizards along those axes. Thus Riedel et al. (2020) identify evolutionary convergence of microhabitat use (at least in climbing forms) across lineages that have split well over 100 million years ago.

In the ninth paper, Delaugerre and Corti (2020) report their survey the reptile fauna on 111 islands and islets surrounding Corsica (France). Forty-three islets are inhabited by one reptile species, 36 of them by the gecko Euleptes europaea. This gecko also inhabits 33 of the 34 islands with two reptile species, and all 12 islands with richer reptile assemblages. Delaugerre and Corti (2020) infer that E. europaea is probably a relict from glacial times when the islets were connected to "mainland" Corsica, and discuss the reasons why was better able to survive in the extreme habitats of these islands better than other squamate species. In the $10^{\text {th }}$ paper Stark et al. (2020) examine the longevities of 740 lizard species, 185 of which are geckos, to test whether nocturnality is associated with longer 
lifespans. They find that geckos generally have higher longevities than other similar-sized lizards, but that nocturnal species are not longer living. We suggest that diurnal lizards have adapted to environments with high UV radiation, and that the high metabolic rates associated with diurnality do not translate to shorter lifespans.

In the $11^{\text {th }}$ paper Gumbs et al. (2020) examine the phylogenetic diversity, and phylogenetic endemism patterns, of geckos in view of these patterns in other taxa, and of human pressure on their habitats. They find high irreplaceable gecko diversity in regions under intense anthropogenic pressures (e.g., southern Asia, southwest Africa, and the Caribbean). Perhaps because of their position as a sister group of all other squamates (except dibamids) geckos harbor more unique phylogenetic diversity than other squamate clades and are generally under greater threat of extinction (Gumbs et al. 2020). Finally, in the $12^{\text {th }}$ paper I examine the ecology and life history of geckos, compared to these of other lizards (Meiri 2020). I find that geckos are relatively small, occur at low latitudes, and are frequently insular lizards, with low activity and preferred temperatures and low lifetime fecundities. Worryingly, the generally small ranges of geckos predispose them to high extinction risk, a consideration that unfortunately is not manifest in formal threat assessments (Meiri 2020).

Geckos are small, nocturnal, and elusive, often hiding in trees, caves, and rock crevices. Thus, despite being the most vocal of reptiles, non commensal species are often very little known, poorly understood, and often not yet found or described by scientists. I hope the Gekkota Mundi symposia, and this special issue, will encourage more systematists, ecologists, evolutionary biologists and conservation biologists and practitioners to study, understand and protect geckos better.

\section{Acknowledgements}

I want to thank the participants and organizers of the Gekkota Mundi symposia, especially Paul Doughty, Erez Maza and Aaron Bauer, and the all the authors who contributed to the special volume for their enthusiasm, helpfulness, and support.

\section{References}

Agarwal, I., Thackerayl, T. and Khandekar, A. 2020. Geckos in the granite: two new geckos (Squamata: Gekkonidae) from rocky, scrub habitats in Rishi Valley, Andhra Pradesh, India. Zootaxa 4838: 451-474.

Boulenger, G.A. (1885). Catalogue of the lizards in the British Museum (Natural History), Volume I. Geckonidae, Eublepharidae, Uroplatidae, Pygopodidae, Agamidae. London: Trustees of the British Museum (Natural History).

Chomdej, S., Suwannapoom, C., Pawangkhanant, P., Pradit, W., Nazarov, R. A., Grismer, L. L. and Poyarkov, N. A. 2020. A new species Cyrtodactytlus Gray (Squamata: Gekkonidae) from western Thailand and the phylogenetic placement of C. inthanon and C. doisuthep. Zootaxa, 4838: 179-209.

Delaugerre, M. J. and Corti, C. 2020. Tiny but "strong": the European leaf-toed gecko, Euleptes europaea, a terrestrial vertebrate able to survive on tiny islets. Israel Journal of Ecology \& Evolution.
Duméril, A.M.C., and Bibron, G. (1836). Erpetologie Générale ou Histoire Naturelle Complete des Reptiles, Volume 3. Paris: Librairie Encyclopédique de Roret.

Gray, J.E. 1845. Catalogue of the specimens of lizards in the collection of the British Museum. London: Trustees of the British Museum/Edward Newman.

Grismer, L. L., Wood, P. L., Grismer, M. S., Quah, E. S. H., Thura, M. K., Oaks, J. R., Lin, A. and Lin, D. Y. 2020a. Integrative taxonomic and geographic variation analyses in $\mathrm{Cyr}$ todactylus aequalis (Squamata: Gekkonidae) from southern Myanmar (Burma): one species, two different stories. Israel Journal of Ecology \& Evolution.

Grismer, L. L., Quah, E. S. and Thura, M. K. 2020b. Origin, diversity, and conservation of karst-associated bent-toed geckos (genus Cyrtodactylus) in Myanmar (Burma). Israel Journal of Ecology and Evolution.

Gumbs, R., Williams, R. C., Lowney, A. M. and Smith, D. 2020. Spatial and species-level metrics reveal global patterns of irreplaceable and imperiled gecko phylogenetic diversity. Israel Journal of Ecology and Evolution.

Karkkainen, D. T., Richards, S. J., Kraus, F., Tjaturadi, B., Krey, K. and Oliver, P. M. 2020. A new species of small Lepidodactylus (Squamata: Gekkonidae) from Salawati Island, Indonesia. Israel Journal of Ecology and Evolution.

Kealley, L., Doughty, P., Edwards, D. and Brennan, I. G. 2020. Taxonomic assessment of two pygopodoid gecko subspecies from Western Australia. Israel Journal of Ecology \& Evolution.

Loveridge, A. 1932. New lizards of the genera Nephrurus and Amphibolurus from Western Australia. Proceedings of the New England Zoological Club 13: 31-34.

Marques, M. P., Ceríaco, L. M. P., Buehler, M. D., Bandeira, S. A., Janota, J. M. and Bauer, A. M. 2020. A revision of the dwarf geckos, genus Lygodactylus (Squamata: Gekkonidae), from Angola, with the description of three new species. Zootaxa 4853: 301-352.

Meiri, S. 2016. Small, rare and trendy: traits and biogeography of lizards described in the 21st century. Journal of Zoology 299: 251-261.

Meiri, S. 2020. What geckos are - an ecological-biogeographic perspective. Israel Journal of Ecology and Evolution, doi: $10.1163 / 22244662-20191075$.

Mohapatra, P. P., Khandekar, A., Dutta, S. K., Mahapatra, C. and Agarwal, I. 2020. A novel, diminutive Hemiphyllodactylus Bleeker, 1860 (Squamata: Gekkonidae) from a sacred grove in Odisha, eastern India. Zootaxa 4852: 485-499.

Oliver, P. M., Brown, R. M., Karin, B. R. and Grismer, L. L. 2020. Mountain endemism in Malesian geckos: can biotic interactions push lizards up hills? Israel Journal of Ecology and Evolution.

Riedel, J., Nordberg, E. and Schwarzkopf, L. 2020. Ecological niche and microhabitat use of Australian geckos. Israel Journal of Ecology and Evolution.

Schlegel, H. 1865. Pygopus gracilis. pp. 229. In: Cope, E.D. On the characters of the higher groups of Reptilia Squamata and especially of the Diploglossa. Proceedings of the National Academy of Sciences 1864, pp. 224-231.

Stark, G., Schwarz, R. and Meiri, S. 2020. Does nocturnal activity prolong gecko longevity? Israel Journal of Ecology and Evolution.

Storr, G.M. 1963. The gekkonid genus Nephrurus in Western Australia, including a new species and three new subspecies. Journal of the Royal Society of Western Australia 46, pp. $85-90$.

Storr, G.M. 1978. Taxonomic notes on the reptiles of the Shark Bay region, Western Australia. Records of the Western Australian Museum 6, pp. 303-318.

Sumontha, M. and Pauwels, O. S. G. 2020. A new leaf-toed gecko (Gekkonidae: Dixonius) from the city of Ranong, southwestern Thailand. Zootaxa 4852: 166-176.

Uetz, P. 2020. The reptile database, http://reptile-database .reptarium.cz, accessed September 21, 2020. 
Uetz, P., Slavenko, A., Meiri, S. and Heinicke, M. 2020. Gecko diversity: a history of global discovery. Israel Journal of Ecology and Evolution http://dx.doi.org/10.1163/22244662-bja10003.

Worthington Wilmer, J., Amey, A. P., McDougall, C., Venz, M.,

Peck, S. and Oliver, P. M. 2020. Comparative mitochondrial phylogeography of two legless lizards (Pygopodidae) from
Queensland's fragmented woodlands. Israel Journal of Ecology and Evolution.

Zhu, X-Y, Chen, G-Y., Roman-Palacios, C., Li, Z. and He, ZQ. 2020. Goniurosaurus gezhi sp. nov., a new gecko species from Guangxi, China (Squamata: Eublepharidae). Zootaxa 4852: 211-222. 